\title{
Rizóbios E ADUbaÇão Nitrogenada NA PRODUÇão DE MUdAS DE MIMOSA TENUIFLORA (WILLD.) POIR.
}

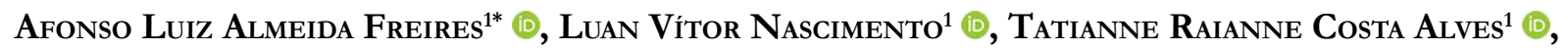

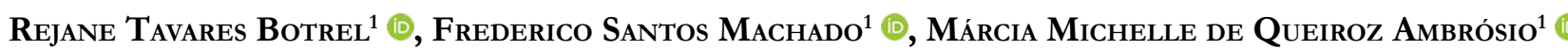

1 Centro de Ciências Agrárias/Universidade Federal Rural do Semi-Árido Universidade Federal Rural do Semi-Árido (UFERSA), Av. Francisco Mota, 572 - Bairro Costa e Silva, Mossoró RN | CEP: 59.625-900

* Autorpara correspondência: afonso_bot@botmail.com

Recebido em 26 de agosto de 2019. Aceito em 30 de julho de 2020. Publicado em 31 de julho de 2020.

Resumo - Objetivou-se com o presente trabalho avaliar o efeito da inoculação de rizóbios e doses de nitrogênio na produção de mudas de Mimosa tenniflora. O ensaio foi conduzido em casa de vegetação, em delineamento experimental inteiramente casualizado, com oito tratamentos: Controle; Inóculo de M. tenuiflora, Inóculo de Piptadenia moniliformis; Inoculante de soja Total Nitro Full ${ }^{\circledR}$ (Bradyrbiz̨obium japonicum); Doses de nitrogênio (70; 140; 210 e $280 \mathrm{mg} \mathrm{dm}^{-3}$ ) e seis repetições. As variáveis analisadas foram comprimento da parte aérea, comprimento da raiz, diâmetro do caule, massa seca da parte aérea, massa seca do caule, massa seca da raiz, massa seca da folha, massa seca total e índice de robustez. Os efeitos dos tratamentos nas variáveis foram analisados mediante a análise de variância, seguida pelo teste de comparação de médias de Scott-Knott ( $\mathrm{p} \leq 0,05)$. Com a caracterização fenotípica dos isolados, as bactérias foram caracterizadas como Rhiz̧obium sp. Na maioria dos parâmetros avaliados, o inóculo de $M$. tenuiflora foi mais eficiente no desenvolvimento das mudas, proporcionando crescimento semelhante a adubação nitrogenada na dose mais indicada $\left(210 \mathrm{mg} \mathrm{dm}^{-3}\right)$. Os rizóbios inespecíficos, de P. moniliformis e o inoculante de soja Total Nitro Full ${ }^{\circledR}(B$. japonicum) não favoreceram o desenvolvimento das mudas de $M$. tenniflora.

Palavras-chave: Jurema preta; Caatinga; Fixação Biológica de Nitrogênio.

\section{RHIZOBIA AND NITROgEN FERTILIZATION ON MIMOSA TENUIFLORA (WILLD.) POIR SEEDLINGS PRODUCTION}

Aвstract - This study evaluated the effect of rhizobia inoculation and nitrogen doses on the production of Mimosa tenniflora seedlings. The experiment was conducted in greenhouse, in a completely randomized experimental design, with eight treatments: control; M. tenuiflora isolate; Piptadenia moniliformis isolate; Total Nitro Full ${ }^{\circledR}$ (Bradyrbizobium japonicum); and four nitrogen doses (70,140, 210, and $280 \mathrm{mg} \mathrm{dm}-3$ ), with six replications each. Shoot height, root length, stem diameter, shoot dry matter, stem dry matter, root dry matter, leaf dry matter, total dry matter and robustness index were assessed. The effects of treatments on the variables were analyzed using analysis of variance, followed by the Scott-Knott means comparison test $(\mathrm{p} \leq 0.05)$. With the phenotypic characterization of the isolates, the bacteria were characterized as Rhizobium sp. In most of the assessed parameters, $M$. tenuiflora isolate was more efficient in promoting seedling growth, with results similar to nitrogen fertilization at the most indicated dose $(210 \mathrm{mg} \mathrm{dm}-3)$. The unspecific isolate of $P$. moniliformis and the commercial

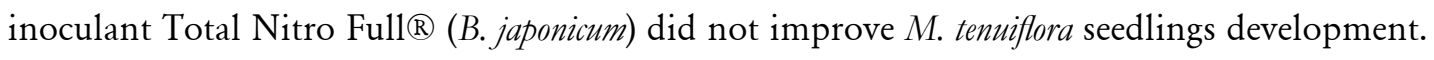

KeYwords: Black Jurema: Caatinga; Biological Nitrogen Fixation.

RHIZOBIo Y FERTILIZACión NITROGENADA EM LA PRODUCióN DE PLÂNTULAS DE MIMOSA TENUIFLORA (WILLD.) POIR.

Resumen - El objetivo de este estudio fue evaluar el efecto de la inoculación con rizobios y las dosis de nitrógeno en la producción de plántulas de Mimosa tenuiflora (Willd.) Poir. El experimento se realizó en un invernadero en un diseño 
completamente al azar con ocho tratamentos: Control; Inóculo de Mimosa tenuiflora; Inóculo de Piptadenia moniliformis; Inoculante total de soja Nitro Full ${ }^{\circledR}$ (Bradyrbizobium japonicum); Dosis de nitrógeno (70; 140; 210 y $280 \mathrm{mg} \mathrm{dm-3)} \mathrm{y} \mathrm{seis}$ repeticiones. Las variables analizadas fueron longitud del brote, longitud de la raíz, diámetro del tallo, masa seca del brote, masa seca del tallo, masa seca de la raíz, masa seca de la hoja, masa seca total e índice de robustez. Los efectos de los tratamientos en las variables se analizaron mediante análisis de varianza, seguido de la prueba de comparación de medias de Scott-Knott $(\mathrm{p} \leq 0,05)$. Con la caracterización fenotípica de los aislamientos, las bacterias se caracterizaron como Rbizobium sp. En la mayoría de los parámetros analizados, el inóculo de Mimosa tenuiflora fue más eficiente en el desarrollo de plántulas, proporcionando un crecimiento similar a la fertilización nitrogenada con mejores resultados (210 mg dm-3). Los rizobios no específicos de Piptadenia moniliformis y el inoculante de soja Total Nitro Full ${ }^{\circ}$ (B.japonicum) no favorecieron el desarrollo de plántulas de M. tenniflora.

Palabras Clave: Jurema preta; Caatinga; Fijación biológica de nitrógeno.

\section{INTRODUÇÃO}

A espécie Mimosa tenuiflora (Willd.) Poir popularmente conhecida como Calumbi, Jurema e Jurema-preta, pertence à família Fabaceae e pode atingir de 5 a 7 metros de altura, com acúleos esparsos, caule ereto ou levemente inclinado (Maia 2004). É uma espécie pioneira, nativa do bioma Caatinga, encontrada com frequência na região semiárida brasileira (Oliveira et al. 2006) e bastante explorada devido seu potencial forrageiro e medicinal (Bezerra et al. 2011).

Devido às diversas utilidades das espécies florestais da Caatinga (EFC), a exploração deste bioma tem se intensificado, causando danos irreversíveis na região semiárida. Nestas áreas, o processo de degradação encontrase acelerado devido à retirada da vegetação para exploração dos recursos naturais (Alves al. 2009) e a falta de conscientização e compromisso com o reflorestamento das áreas. No processo de recuperação de áreas degradadas, a introdução de espécies da família Fabaceae é essencial pois, por meio da associação com bactérias, fixam o nitrogênio atmosférico, possibilitando o crescimento das plantas em condições adversas (Tavares et al. 2016) e minimizando os impactos ambientais ocasionados pelos adubos químicos (Maia e Scotti 2010).

A fixação biológica de nitrogênio (FBN) é um processo onde o rizóbio, no sistema de simbiose com a planta, promove o processo de fixação de nitrogênio, do qual as plantas se beneficiam, como constataram Ferreira et al. (2012), onde concluíram que a estirpe de rizóbio UFLA0271 é eficiente na fixação de nitrogênio em Mimosa caesalpiniifolia, e a estirpe UFLA01659 em Mimosa pudica e Leucaena leucocephala, em vaso com solo. A eficiência da fixação é inconstante, sendo influenciada, dentre outros fatores, pela especificidade hospedeira (Antunes et al. 2011). Quando eficiente, a associação com bactérias fixadoras de nitrogênio pode reduzir e até eliminar o uso de adubos nitrogenados, reduzindo os custos de produção (Maia e Scotti 2010). Além disso, a FBN pode ajudar na sobrevivência das plantas no campo (Mendes et al. 2013).

Porém, existem entraves, como a falta de inoculantes comerciais à base de rizóbios para as leguminosas florestais da Caatinga. Estes inoculantes são produzidos apenas em caráter experimental pela Empresa Brasileira de Pesquisa Agropecuária (EMBRAPA), sem valor comercial, e são voltados para a pesquisa científica da empresa e de seus parceiros nas instituições de pesquisa, desenvolvimento e extensão tecnológica (Embrapa 2016). A comercialização existe somente para as espécies cultivadas, como por exemplo, Glycine max L. e Phaseolus vulgaris L. É importante averiguar a especificidade das bactérias e, se rizóbios isolados de outras espécies vegetais apresentam eficiência para M. tenuiflora.

Lima et al. (2015) avaliaram o desenvolvimento inicial e a sobrevivência de espécies arbóreas plantadas na Caatinga, e em jazidas de piçarra utilizada na produção de petróleo, no Oeste Potiguar. Estes autores concluíram que as espécies nodulantes superaram as demais quanto às taxas de sobrevivência e de crescimento, altura total 
e diâmetro. Dentre as 20 espécies avaliadas neste estudo, a $M$. tenuiflora se destacou, chegando a três metros de altura e $100 \%$ de sobrevivência, aos 20 meses após o plantio, apresentando potencial para estabelecimento nessas áreas degradadas. Chaves et al. (2006a) concluíram que as mudas de Anadenanthera macrocarpa, inoculadas com rizóbio apresentaram melhor desenvolvimento em relação às adubadas com N. Em M. caesalpiniifolia, Tavares et al. (2016) observaram que o rizóbio favoreceu o crescimento das mudas em área degradada e Fernandes et al. (2017) verificaram que no campo, o Bradyrbizobium elkanii proporcionou às mudas de Enterolobium contortisiliquum maior potencial de sobrevivência e crescimento no pós-plantio.

A adubação nitrogenada é um fator importante na recomposição de ecossistemas degradados, devendo ser criteriosamente considerada para que as mudas não tenham o seu crescimento afetado pela falta, ou apresentem desordem nutricional pelo excesso desse nutriente (Smarsi et al. 2011). Informações sobre esse tema, considerando espécies da Caatinga, ainda são insuficientes, existindo grande dificuldade de se fazer recomendações específicas, em virtude da grande diversidade de espécies neste bioma, (Dutra et al. 2015) e dos poucos estudos envolvendo tais espécies.

Diante do exposto, objetivou-se verificar o efeito da inoculação de rizóbios e diferentes doses de nitrogênio na produção de mudas de $M$. tenuiflora.

\section{Material e Métodos}

O experimento foi conduzido na Universidade Federal Rural do Semi-Árido (UFERSA) no município de Mossoró, RN. Os nódulos de $M$. tenuiflora foram coletados manualmente, das raízes de matriz localizada na UFERSA, Latitude: $05^{\circ} 12^{\prime} 21,5^{\prime}$ S Longitude: $037^{\circ} 19^{\prime} 11.3^{\prime}$ W. Já os nódulos oriundos de P. moniliformis foram coletados na Fazenda experimental Rafael Fernandes em Alagoinha, zona rural de Mossoró 503’44.4” S; 37²4’03.0” W.

No laboratório de Microbiologia da UFERSA realizou-se a obtenção dos isolados. Os nódulos foram lavados para retirada de solo e, em seguida, realizada a desinfestação superficial (álcool 70 \%, hipoclorito de sódio $1 \%$, e lavagem em água destilada esterilizada). Um nódulo ativo, devidamente desinfestado, foi colocado em um tubo de ensaio contendo 3,0 mL de água destilada esterilizada e, posteriormente, triturado com o auxílio de um bastão de vidro flambado. A suspensão foi transferida para placas de Petri contendo meio de cultura Levedura Manitol Ágar (LMA) com ajuda de alça bacteriológica. As placas foram mantidas em estufa do tipo BOD (Biochemical Oxygen Demand) a $28 \pm 2{ }^{\circ} \mathrm{C}$ para o crescimento das colônias.

Os isolados bacterianos das duas espécies foram caracterizados morfofisiologicamente, e observou-se o tempo de crescimento das colônias, $\mathrm{pH}$ (em meio de cultura LMA), com o indicador azul de bromotimol, diâmetro, forma, elevação, borda, aparência e cor da colônia, elasticidade e tipo de muco. Na avaliação do diâmetro da colônia utilizou-se um paquímetro digital, onde foram feitas medições de dez colônias do isolado, e posteriormente, a média das medições. A forma, elevação e borda das colônias foram avaliadas visualmente, conforme metodologia proposta por Martins et al. (1997). Com o auxílio de uma alça de platina bacteriológica, verificou-se o tipo de muco e a elasticidade da colônia.

Para o preparo dos inóculos, os isolados purificados foram repicados para o meio de cultura YMA (yeast mannitol ágar) e, após cinco dias de incubação, foram repicados para o meio líquido yeast mannitol (YM), que foi mantido em estufa incubadora tipo BOD, a $28 \pm 2{ }^{\circ} \mathrm{C}$, sendo agitado diariamente por seis dias.

O experimento de produção de mudas foi conduzido em casa de vegetação, na UFERSA, cujas coordenadas geográficas são: latitude: $5^{\circ} 12^{\prime} 48^{\prime \prime} \mathrm{S}$; longitude: $37^{\circ} 18^{\prime} 44^{\prime \prime} \mathrm{W}$, e altitude: $37 \mathrm{~m}$ acima do nível do mar. A unidade experimental foi constituída por saco de polietileno preto, contendo 1,4 $\mathrm{kg}$ de areia lavada e autoclavada. As sementes de $M$. tenuiflora foram coletadas na fazenda experimental Rafael Fernandes, submetidas ao processo de superação de dormência, por meio da imersão em água quente $\left(100{ }^{\circ} \mathrm{C}\right.$ por 5 minutos) (Benedito et al. 2017), e desinfestação superficial (álcool $70 \%$ e hipoclorito de sódio a 2,5\% por 1 minuto). A semeadura foi realizada com três sementes por saco e, antes da aplicação dos tratamentos, foi feito o desbaste, deixando apenas 
uma planta por saco. Os tratamentos foram aplicados 25 dias após a semeadura, após a emergência das folhas verdadeiras, na região próxima ao colo das plântulas.

O delineamento utilizado foi o inteiramente casualizado, com oito tratamentos e seis repetições. Os tratamentos foram: Controle (meio de cultura levedura manitol); inóculo oriundo de M. tenuiflora $\left(3,64 \times 10^{8}\right.$ $\mathrm{UFC} / \mathrm{mL}$ ); inóculo oriundo de P. moniliformis $\left(3,84 \times 10^{8} \mathrm{UFC} / \mathrm{mL}\right)$; inoculante Total Nitro Full ${ }^{\circledR}$ (Bradyrbizobium japonicum) (7x10 $\mathrm{UFC} / \mathrm{mL})$; doses de nitrogênio 70; 140; 210 e $280 \mathrm{mg} \mathrm{dm}^{-3}$ (fonte: sulfato de amônio). As doses, e os inóculos foram aplicados na quantidade de $20 \mathrm{~mL}$ por saco, logo após o transplantio das mudas. As doses de nitrogênio e a solução nutritiva proposta por Hoagland e Arnon (1950), modificada sem N (Machado et al. 1998), foram aplicadas semanalmente.

Todas as unidades experimentais foram analisadas durante as quatro avaliações (aos 55, 85, 115, 145 dias) após a semeadura, onde se mediu o comprimento da parte aérea (CPA) com auxílio de uma régua graduada, em centímetros, diâmetro do colo (D), com auxílio de um paquímetro digital, e o número de folhas (NF).

$\mathrm{Na}$ ocasião da desinstalação do experimento, aos 175 dias após a semeadura, realizou-se avaliação das variáveis: comprimento da parte aérea (CPA), comprimento de raiz (CR), diâmetro do caule (DC), massas secas da raiz (MSR), parte aérea (MSPA), caule (MSC), folhas (MSF) e total (MST) após secagem em estufa de circulação de ar forçada, a $70{ }^{\circ} \mathrm{C}$, até atingir massa constante. $\mathrm{O}$ índice de robustez (IR), que é um importante indicador da qualidade das mudas (Mañas 2009), foi obtido pela relação entre o comprimento da parte aérea e o diâmetro do caule (Cadorin et al. 2015).

Os dados experimentais qualitativos foram submetidos à análise de variância (ANOVA), seguido pelo teste de comparação de médias de Scott-knott a $5 \%$ de probabilidade. Também foi realizada a análise de regressão para os fatores quantitativos (doses 70, 140, 210 e $280 \mathrm{mg} \mathrm{dm}^{-3}$ ) de nitrogênio.

\section{Resultados e Discussão}

Com base nas variáveis analisadas para a caracterização morfofisiológica, os isolados foram identificados como Rhizobium sp., de acordo com Martins et al. (1997), por apresentar crescimento rápido, sendo inferior a 72 horas, produção de muco viscoso e diâmetro de colônia maior que $2 \mathrm{~mm}$, com formato circular. Ocorreu alteração aparente do $\mathrm{pH}$ (mudança de coloração) quando o isolado foi cultivado em meio YMA com azul de bromotimol, tornando o meio com coloração amarelo devido a aquisição rápida de carboidratos, sendo característica de rizóbios de crescimento rápido, como é o caso do Rhiz̧obium sp. Na produção de mudas, aos 175 dias após a semeadura, verificou-se na maioria das variáveis analisadas efeito significativo pelo teste $\mathrm{F}(\mathrm{p}>0,01)$, exceto o CR (Tabela 1).

Tabela 1. Resumo da análise de variância (Quadrado Médio) do comprimento da parte aérea (CPA, $\mathrm{mm}$ ), comprimento da raiz $(\mathrm{CR}, \mathrm{mm})$, diâmetro do caule $(\mathrm{D}, \mathrm{cm})$, massa seca da parte aérea (MSPA, g), massa seca do caule (MSC, g), massa seca da raiz (MSR, g), massa seca da folha (MSF, g), massa seca total (MST, g) e índice de robustez (IR) das mudas de Mimosa tenuiflora (Willd.) Poir sob inoculação de rizóbios e adubação nitrogenada.

\begin{tabular}{lcccccccccc}
\hline FV & GL & CPA & CR & D & MSPA & MSC & MSR & MSF & MST & IR \\
\hline T & 7 & $275,4^{* * *}$ & $40,1^{\text {ns }}$ & $1,9^{* * *}$ & $3,6^{* *}$ & $0,4^{* *}$ & $2,2^{*}$ & $2,1^{*}$ & $11,1^{* * *}$ & $0,1^{* * *}$ \\
R & 40 & 39,3 & 51,04 & 0,2 & 1,0 & 0,1 & 0,8 & 0,4 & 164,4 & 0,02 \\
TA & 47 & 3500,6 & 2322,3 & 23,6 & 67,4 & 70,4 & 48,5 & 30,9 & 54,4 & 1,4 \\
CV & & 37,6 & 22,8 & 17,7 & 62,3 & 81,2 & 60,7 & 53,1 & 54,4 & 24,3 \\
\hline
\end{tabular}

$* * \mathrm{e}^{*}$ Efeito significativo pelo teste de Skott-Knott ao nível de 1 e $5 \%$ de probabilidade, respectivamente; ns - não significativo. CV = coeficiente de variação. $\mathrm{FV}=$ fonte de variação; $\mathrm{GL}=$ grau de liberdade; $\mathrm{T}=$ tratamento; $\mathrm{R}=$ resíduo; $\mathrm{TA}=$ total ajustado; $\mathrm{CV}=$ coeficiente de variação (\%). 
Os tratamentos que proporcionaram os melhores resultados de CPA de $M$. tenuiflora foram o inóculo de $M$. tenuiflora (específico), e as doses de nitrogênio 140; 210 e $280 \mathrm{mg} \mathrm{dm}^{-3}$, sendo estatisticamente iguais (Tabela 2). Este resultado demonstrou que o rizóbio obtido de nódulos de $M$. tenuiflora é favorável ao crescimento de mudas desta espécie florestal, e mostrou-se equivalente as maiores doses de nitrogênio.

Tabela 2. Comprimento da parte aérea de mudas de Mimosa tenuiflora (Willd.) Poir aos 55, 85, 115, 145 e 175 dias após a semeadura.

\begin{tabular}{|c|c|c|c|c|c|}
\hline \multirow{3}{*}{ Tratamentos } & \multicolumn{5}{|c|}{ Comprimento da parte aérea $(\mathrm{mm})$} \\
\hline & \multicolumn{5}{|c|}{ Dias após a semeadura } \\
\hline & 55 & 85 & 115 & 145 & 175 \\
\hline Controle & $2,41 \mathrm{a}$ & $4,05 \mathrm{~b}$ & $5,56 \mathrm{~b}$ & $7,17 \mathrm{~b}$ & $9,23 \mathrm{~b}$ \\
\hline Inóculo de $M$. tenuiflora & $2,42 \mathrm{a}$ & $4,08 \mathrm{~b}$ & $8,87 \mathrm{a}$ & $14,53 \mathrm{a}$ & $26,3 \mathrm{a}$ \\
\hline Inóculo e $P$. moniliformis & $2,26 \mathrm{a}$ & $3,63 \mathrm{~b}$ & $5,40 \mathrm{~b}$ & $6,90 \mathrm{~b}$ & $8,62 \mathrm{~b}$ \\
\hline Inoculante Total Nitro ${ }^{\circledR}$ (B.japonicum) & $2,80 \mathrm{a}$ & $4,56 \mathrm{~b}$ & $7,11 \mathrm{~b}$ & $8,90 \mathrm{~b}$ & $11,83 \mathrm{~b}$ \\
\hline Dose de N $70 \mathrm{mg} \mathrm{dm}^{-3}$ & $2,77 \mathrm{a}$ & $5,66 \mathrm{a}$ & $9,66 \mathrm{a}$ & $11,88 \mathrm{a}$ & $13,35 \mathrm{~b}$ \\
\hline Dose de N $140 \mathrm{mg} \mathrm{dm}^{-3}$ & $2,75 \mathrm{a}$ & $5,21 \mathrm{a}$ & $10,76 \mathrm{a}$ & $13,47 \mathrm{a}$ & $19,50 \mathrm{a}$ \\
\hline Dose de N $210 \mathrm{mg} \mathrm{dm}^{-3}$ & $3,11 \mathrm{a}$ & $6,16 \mathrm{a}$ & $11,74 \mathrm{a}$ & 17,14 a & $23,57 \mathrm{a}$ \\
\hline Dose de N $280 \mathrm{mg} \mathrm{dm}^{-3}$ & $3,04 \mathrm{a}$ & $4,91 \mathrm{a}$ & $8,52 \mathrm{a}$ & $12,26 \mathrm{a}$ & $20,92 \mathrm{a}$ \\
\hline Coeficiente de Variação (\%) & 26,24 & 28,69 & 37,00 & 27,75 & 37,63 \\
\hline
\end{tabular}

Médias seguidas pela mesma letra dentro da coluna não diferiram entre si pelo teste de Scott-Knott a 5 \% de probabilidade.

Verificou-se simbiose de maneira efetiva por parte do rizóbio de $M$. tenuiflora, a partir dos 115 dias, quando o inóculo específico proporcionou comprimento da parte aérea das mudas semelhante às doses de N. Este comportamento provavelmente ocorreu devido à bactéria ser um organismo que carece de um tempo para o estabelecimento da interação. Nobre (2008) relata que é necessário de 20 a 30 dias para membros da família Fabaceae apresentarem indícios de nódulos no sistema radicular, atrasando o início do processo de FBN. Se o período de avaliação tivesse sido ampliado, provavelmente, as mudas inoculadas com rizóbio de $M$. tenuiflora apresentariam maiores valores de CPA, já que no início do estabelecimento, as bactérias atuam competindo com a planta por nutrientes e carboidrato, fixando pouco N (Dias et al. 2012), sendo incrementado de forma gradativa, conforme verificado durante as avaliações. Inicialmente há um gasto energético para a formação de nódulos nas raízes das leguminosas, em seguida, a bactéria passa a fixar o nitrogênio atmosférico em compostos orgânicos, que são utilizados pela planta (Silva et al. 2006). Por este motivo, inicialmente, o crescimento das plantas inoculadas com rizóbios são pouco pronunciadas. $\mathrm{O} \mathrm{N}$-mineral fornecido pela adubação pode suprir a demanda inicial das mudas antes da formação dos nódulos, porém após esse período a simbiose é mais eficiente pois a bactéria é um habitante natural do solo, multiplica-se neste habitat, trazendo benefícios no crescimento das plantas, pode ser biocontroladoras, além de ser uma tecnologia simples, e que não polui o ambiente. Já grande parte do N-mineral, após aplicado, pode ser perdido por volatilização e lixiviação (Cameron et al. 2013).

O aumento do CPA de mudas de espécies florestais da família Fabaceae é condicionado pela inoculação com bactérias promotoras de crescimento em plantas, favorecendo o aumento da nodulação, fixação biológica de $\mathrm{N}$, e crescimento das plantas dessa família botânica (Araújo et al. 2010). Mendes et al. (2013) também constataram que mudas de M. caesalpiniifolia inoculadas com rizóbio apresentaram melhor desenvolvimento a partir dos 90 dias. Resultado semelhante foi obtido em mudas de Enterolobium contortisiliqum, que foram inoculadas com rizóbio, e adubadas com nitrogênio sintético, cultivadas durante 80 dias. Os pesquisadores também não observaram diferença estatística entre o uso do rizóbio, e o nitrogênio sintético na altura das plantas em campo, antes dos 90 dias de semeadura (Fernandes et al. 2017). 
Observou-se aos 175 dias após a semeadura, que as mudas onde se aplicou-se o inóculo de $M$. tenuiflora, apresentaram maiores diâmetros dos caules desta espécie florestal (Tabela 3), diferindo estatisticamente dos demais tratamentos. Este comportamento ocorre devido a presença dos simbiontes que, através da fixação biológica de nitrogênio proporcionam às mudas efeito progressivo no desenvolvimento do diâmetro do caule (Vieira e Souza 2011) e das raízes. Isto se deve a fixação do N e a biossíntese de fito-hormônios pelas bactérias, que são considerados os principais mecanismos utilizados pelas bactérias para promover o crescimento de plantas (Lucangeli e Bottini 1997). Segundo Fernandes et al. (2017) este estímulo também possibilitará maior capacidade de sobrevivência das mudas em campo. Os demais tratamentos onde se inoculou rizóbios se comportaram igual ao controle, ressaltando que os rizóbios obtidos de outras espécies não apresentaram melhorias no DC de M. tenuiflora. As mudas com menor diâmetro, e altura elevada, possuem menor capacidade de sobrevivência no campo, sendo melhor a obtenção de mudas com crescimento equilibrado, evitando assim, o tombamento das plantas (Delarmelina et al. 2015).

Tabela 3. Diâmetro (mm) do caule de mudas de Mimosa tenuiflora (Willd.) Poir aos 55, 85, 115, 145 e 175 dias após a semeadura.

\begin{tabular}{|c|c|c|c|c|c|}
\hline \multirow{3}{*}{ Tratamentos } & \multicolumn{5}{|c|}{ Diâmetro do colo } \\
\hline & \multicolumn{5}{|c|}{ Dias após a semeadura } \\
\hline & 55 & 85 & 115 & 145 & 175 \\
\hline Controle & $0,86 \mathrm{a}$ & $0,73 \mathrm{c}$ & $1,45 \mathrm{~b}$ & $1,04 \mathrm{c}$ & $2,14 \mathrm{c}$ \\
\hline Inóculo de M. tenuiflora & $0,89 \mathrm{a}$ & $0,92 \mathrm{c}$ & $1,92 \mathrm{a}$ & $2,48 \mathrm{a}$ & $3,75 \mathrm{a}$ \\
\hline Inóculo e $P$. moniliformis & $0,75 \mathrm{~b}$ & $1,20 \mathrm{~b}$ & $1,35 \mathrm{~b}$ & $1,72 \mathrm{~b}$ & $2,06 \mathrm{c}$ \\
\hline Inoculante Total $\mathrm{Nitro}^{\circledR}$ (B. japonicum) & $0,93 \mathrm{a}$ & $1,44 \mathrm{a}$ & $1,63 \mathrm{~b}$ & $2,14 \mathrm{a}$ & $2,38 \mathrm{c}$ \\
\hline Dose de $\mathrm{N} 70 \mathrm{mg} \mathrm{dm}^{-3}$ & $0,88 \mathrm{a}$ & $1,48 \mathrm{a}$ & $2,02 \mathrm{a}$ & $2,38 \mathrm{a}$ & $2,76 \mathrm{~b}$ \\
\hline Dose de N $140 \mathrm{mg} \mathrm{dm}^{-3}$ & $0,75 \mathrm{~b}$ & $1,38 \mathrm{a}$ & $1,97 \mathrm{a}$ & $2,42 \mathrm{a}$ & $3,02 \mathrm{~b}$ \\
\hline Dose de N $210 \mathrm{mg} \mathrm{dm}^{-3}$ & $0,82 \mathrm{~b}$ & $1,61 \mathrm{a}$ & $1,98 \mathrm{a}$ & $2,56 \mathrm{a}$ & $3,20 \mathrm{~b}$ \\
\hline Dose de N $280 \mathrm{mg} \mathrm{dm}^{-3}$ & $0,79 \mathrm{~b}$ & $1,24 \mathrm{~b}$ & $1,64 \mathrm{~b}$ & $2,24 \mathrm{a}$ & $2,96 \mathrm{~b}$ \\
\hline Coeficiente de variância (\%) & 14,59 & 15,95 & 23,08 & 24,14 & 17,77 \\
\hline
\end{tabular}

Médias seguidas pela mesma letra dentro da coluna não diferiram entre si pelo teste de Scott-Knott a $5 \%$ de probabilidade.

Apesar da expectativa dos inoculantes não específicos de $M$. tenniflora apresentarem algum efeito positivo nas mudas desta espécie, isto não foi observado. Se os rizóbios não específicos apresentassem algum efeito nas mudas, poderia facilitar a produção de mudas de espécies florestais da Caatinga (EFC), uma vez que existem diferentes inoculantes comerciais a base de espécies cultivadas sendo comercializados. O rizóbio de P. moniliformis, também EFC, não proporcionou incremento no diâmetro do caule de $M$. tenuiflora. Estes resultados confirmam a informação exibida na literatura, a respeito da especificidade dos rizóbios (Carvalho et al. 2008), embora alguns pesquisadores já tenham obtido sucesso no desenvolvimento de mudas de espécies florestais com a inoculação de rizóbios isolados de outras espécies, ou seja, não específicos (Ferreira et al. 2012).

Trabalhando com Enterolobium contortisiliquum, Fernandes et al. (2017) verificaram que as plantas inoculadas com bactérias diazotróficas, diferiram estatisticamente dos tratamentos com adubação nitrogenada, e do tratamento controle, corroborando com os resultados obtidos neste trabalho. Em outra espécie florestal da Caatinga $(A$. macrocarpa) as mudas inoculadas com rizóbio também diferiram positivamente da adubação nitrogenada (Chaves et al. 2006b).

Na MSR, a aplicação de rizóbio de $M$. tenuiflora foi estatisticamente igual aos tratamentos com nitrogênio sintético, e superior aos demais tratamentos com rizóbios não específicos, e o controle (Tabela 4). Em mudas de Acacia mangium, a inoculaзго de rizybio tambйm proporcionou MSR similar a adubазго nitrogenada 
(Jayakumar e Tan 2006). O sucesso do inóculo específico em relação aos inespecíficos é explicado em razão do processo simbiótico ser espécie-específico, o que dificulta a eficácia desta relação com outras espécies hospedeiras. Para isso, é fundamental a seleção de estirpes que influenciam de maneira positiva, melhorando a capacidade da FBN (Bellini et al. 2014).

Tabela 4 Massas secas das raízes (MSR), caules (MSC), folhas (MSF), total (MST) e o índice de robustez (IR) de mudas de Mimosa tenuiflora (Willd.) Poir aos 175 dias após a semeadura.

\begin{tabular}{|c|c|c|c|c|c|}
\hline Tratamentos & MSR (g) & $\operatorname{MSC}(g)$ & MSF (g) & MST (g) & IR \\
\hline Controle & $0,85 \mathrm{~b}$ & $0,16 \mathrm{~b}$ & $0,65 \mathrm{~b}$ & $1,741 \mathrm{~b}$ & $0,44 \mathrm{~b}$ \\
\hline Inóculo de $M$. tenuiflora & $2,28 \mathrm{a}$ & $0,88 \mathrm{a}$ & $1,81 \mathrm{a}$ & $5,09 \mathrm{a}$ & $0,67 \mathrm{a}$ \\
\hline Inóculo de $P$. moniliformis & $0,64 \mathrm{~b}$ & $0,13 \mathrm{~b}$ & $0,46 \mathrm{~b}$ & $1,28 \mathrm{~b}$ & $0,42 \mathrm{~b}$ \\
\hline $\begin{array}{l}\text { Inoculante Total Nitro Full® } \\
\text { (B. japonicum) }\end{array}$ & $1,02 \mathrm{~b}$ & $0,18 \mathrm{~b}$ & $0,74 \mathrm{~b}$ & $2,07 \mathrm{~b}$ & $0,49 \mathrm{~b}$ \\
\hline Dose de $\mathrm{N} 70 \mathrm{mg} \mathrm{dm}^{-3}$ & $1,53 \mathrm{a}$ & $0,28 \mathrm{~b}$ & $0,92 \mathrm{~b}$ & $2,80 \mathrm{~b}$ & $0,49 \mathrm{~b}$ \\
\hline Dose de N $140 \mathrm{mg} \mathrm{dm}^{-3}$ & $2,23 \mathrm{a}$ & $0,41 \mathrm{~b}$ & $1,54 \mathrm{a}$ & $4,18 \mathrm{a}$ & $0,65 \mathrm{a}$ \\
\hline Dose de N $210 \mathrm{mg} \mathrm{dm}^{-3}$ & $1,69 \mathrm{a}$ & $0,60 \mathrm{a}$ & $1,50 \mathrm{a}$ & $3,89 \mathrm{a}$ & $0,73 \mathrm{a}$ \\
\hline Dose de N $280 \mathrm{mg} \mathrm{dm}^{-3}$ & $1,69 \mathrm{a}$ & $0,52 \mathrm{a}$ & $2,04 \mathrm{a}$ & $4,04 \mathrm{a}$ & $0,68 \mathrm{a}$ \\
\hline CV (\%) & 60,72 & 81,29 & 53,14 & 54,46 & 24,37 \\
\hline
\end{tabular}

Médias seguidas pela mesma letra dentro da coluna não diferiram entre si pelo teste de Scott-Knott a $5 \%$ de probabilidade.

O rizóbio de $M$. tenuiflora proporcionou maior peso de MSC, diferindo dos inóculos comercial Total Nitro Full ${ }^{\circledR}$ (B. japonicum), de P. moniliformis, e das doses de nitrogênio 70 e $140 \mathrm{mg} \mathrm{dm}^{-3}$. Porém, foi estatisticamente semelhante a adubação com as doses 210 e $280 \mathrm{mg} \mathrm{dm}^{-3}$. Vieira e Souza (2011) também verificaram na matéria seca do caule que a inoculação de rizóbio não diferiu da adubação nitrogenada nas espécies florestais Swartzia argentea e Swartzía laevicarpa, após 204 e 185 dias respectivamente, apesar de ter apresentado média superior aos tratamentos com adubação, fato que também ocorreu neste trabalho. A prática da inoculação com bactérias fixadoras de nitrogênio torna a muda com caules mais vigorosos, resultando em maior MSC (Vieira e Souza 2011).

Para o parâmetro MSF, o rizóbio de $M$. tenuiflora foi superior a dose de $70 \mathrm{mg} \mathrm{dm}^{-3}$ de nitrogênio, os inóculos de P. moniliformis, inoculante comercial Total Nitro Full ${ }^{\circledR}$ (B.japonicum) e o tratamento controle, no entanto, foram iguais as doses 140, 210 e $280 \mathrm{mg} \mathrm{dm}^{-3}$ (p<0,01) (Tabela 4). Vieira e Souza (2011) quando trabalharam com $S$. laevicarpa, verificaram que o peso seco das folhas foi favorecido pelos tratamentos com inoculação do rizóbio específico de $S$. laevicarpa, e adubação com $\mathrm{N}$, apresentando-se superior ao tratamento controle.

A MST das mudas foi superior nos tratamentos inóculo de $M$. tenniflora e doses de nitrogênio (140, 210 e 280 $\left.\mathrm{mg} \mathrm{dm}{ }^{-3}\right)$. A utilização de mudas inoculadas influencia diretamente na produção da biomassa seca, mostrando-se interessante para recuperação de áreas degradadas por contribuir na deposição de matéria orgânica no solo, que através da mineralização e ciclagem de nutrientes, favorece a melhoria das características do solo (Almeida et al. 2013). Além disso, mudas mais desenvolvidas certamente terão maior capacidade de sobrevivência em campo, exigindo menos gastos com manutenção. Avaliando mudas de Sesbania virgata, Ferreira et al. (2015) também não verificaram diferença entre rizóbios e a adubação nitrogenada. Para a espécie nativa da Caatinga $A$. macrocarpa, o resultado divergiu deste trabalho, tendo o rizóbio proporcionado maior incremento na MST em relação as doses de $\mathrm{N}$ (Chaves et al. 2006b).

$\mathrm{O}$ inóculo de $M$. tenuiflora, e as três maiores doses de $\mathrm{N}\left(140,210\right.$ e $\left.280 \mathrm{mg} \mathrm{dm}^{-3}\right)$ proporcionaram maiores valores de IR, sendo estatisticamente superiores a dose de $70 \mathrm{mg} \mathrm{dm}^{-3} \mathrm{de} \mathrm{N}$, e os isolados rizobianos de $P$. moniliformis e B. japonicum (Total Nitro Full ${ }^{\circledR}$ ). Efeito positivo do inóculo de $M$. tenuiflora e da adubação nitrogenada 
também foi verificado em mudas de Inga laurina para o IR, que apresentaram médias superiores ao tratamento controle (Góes et al. 2015).

$\mathrm{Na}$ análise de regressão, verificou-se que as doses de $\mathrm{N}$ se ajustaram ao modelo linear em todos os parâmetros analisados. Houve variação no CPA de 9,23 a 23,57, sinalizando que este parâmetro respondeu a adubação nitrogenada (Figura 1A). Chaves et al. (2003) verificaram, ao trabalhar com substrato constituído por resíduos agroindustriais em mudas de Sesbania virgata, que com o aumento das doses de $\mathrm{N}$, houve maior incremento no comprimento da parte aérea. Mudas de $M$. caesalpiniifolia apresentaram aumento linear na altura, conforme o acréscimo das doses de $\mathrm{N}$ (Marques et al. 2006). As mudas desta espécie, adubadas com $100 \mathrm{mg} \mathrm{dm}^{-3}$ atingiram em média 52,19 cm de comprimento da parte aérea. Já as plantas de $M$. tenuiflora, caso tivessem sido adubadas com a mesma quantidade de $\mathrm{N}$, possivelmente teriam atingido média de 15,75 cm.

Figura 1. Comprimento da parte aérea (A), Diâmetro do caule (B), Massa seca do caule (C) e Massa seca das folhas (D) das mudas de Mimosa tenuiflora, em resposta a aplicação de diferentes doses de nitrogênio após 175 dias.
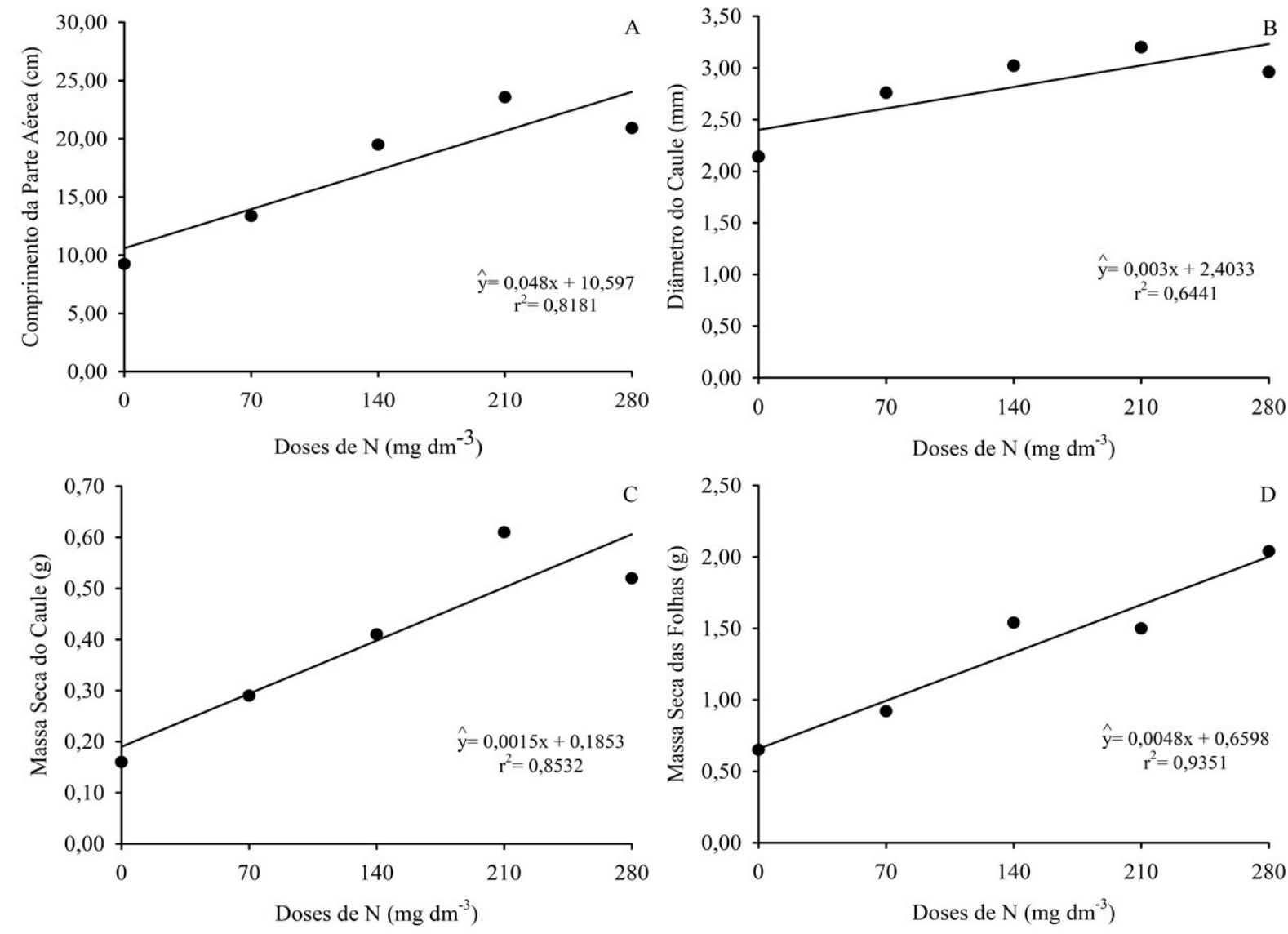

A adubação nitrogenada também proporcionou aumento linear no diâmetro do caule das mudas de $M$. tenuiflora (Figura 1B). Observou-se que mesmo não obtendo resposta quadrática, já houve indicativo de que a dose $280 \mathrm{mg} \mathrm{dm}^{-3}$ de nitrogênio tenha provocado uma moderada queda no desenvolvimento deste parâmetro, para a espécie estudada. Marques et al. (2006) verificaram em mudas de Dalbergia nigra, cultivadas em cambissolo, que os valores dessa característica aumentaram linearmente com as doses, atingindo, na dose de $100 \mathrm{mg} \mathrm{dm}^{-3}, 3,85 \mathrm{~mm}$. No presente trabalho, se estimado a mesma dose $\left(100 \mathrm{mg} \mathrm{dm}^{-3}\right)$ o diâmetro das mudas de M. tenuiflora atingiria $2,70 \mathrm{~mm}$.

Sobre a MSC, verificou-se que as doses de nitrogênio provocaram aumento linear ( $\mathrm{p}<0,05)$. Mudas de Calophyllum brasiliense apresentaram comportamento diferente, pois o maior peso seco do caule foi atingido na dose de $40 \mathrm{mg} \mathrm{dm}^{-3} \mathrm{de} \mathrm{N}$, e o menor peso, na dose de $160 \mathrm{mg} \mathrm{dm}^{-3}$, ajustando-se assim, ao modelo quadrático 
(Ciriello et al. 2014). Espécies nativas apresentam exigências nutricionais distintas, dificultando a transferência de experiências. Mas, estas podem servir para orientação de trabalhos com espécies pouco estudadas (Belapart et al. 2013). A resposta da MSC no incremento das doses de N, pode ser explicada pelo efeito do elemento sobre a altura de plantas, uma vez que nem mesmo a MSR foi afetada pelo incremento de doses de N (Belapart et al. 2013).

Figura 2. Massa seca da parte aérea (A), Massa seca total (B) e Índice de robustez (C) das mudas de Mimosa tenuiflora, em resposta a aplicação de diferentes doses de nitrogênio após 175 dias.
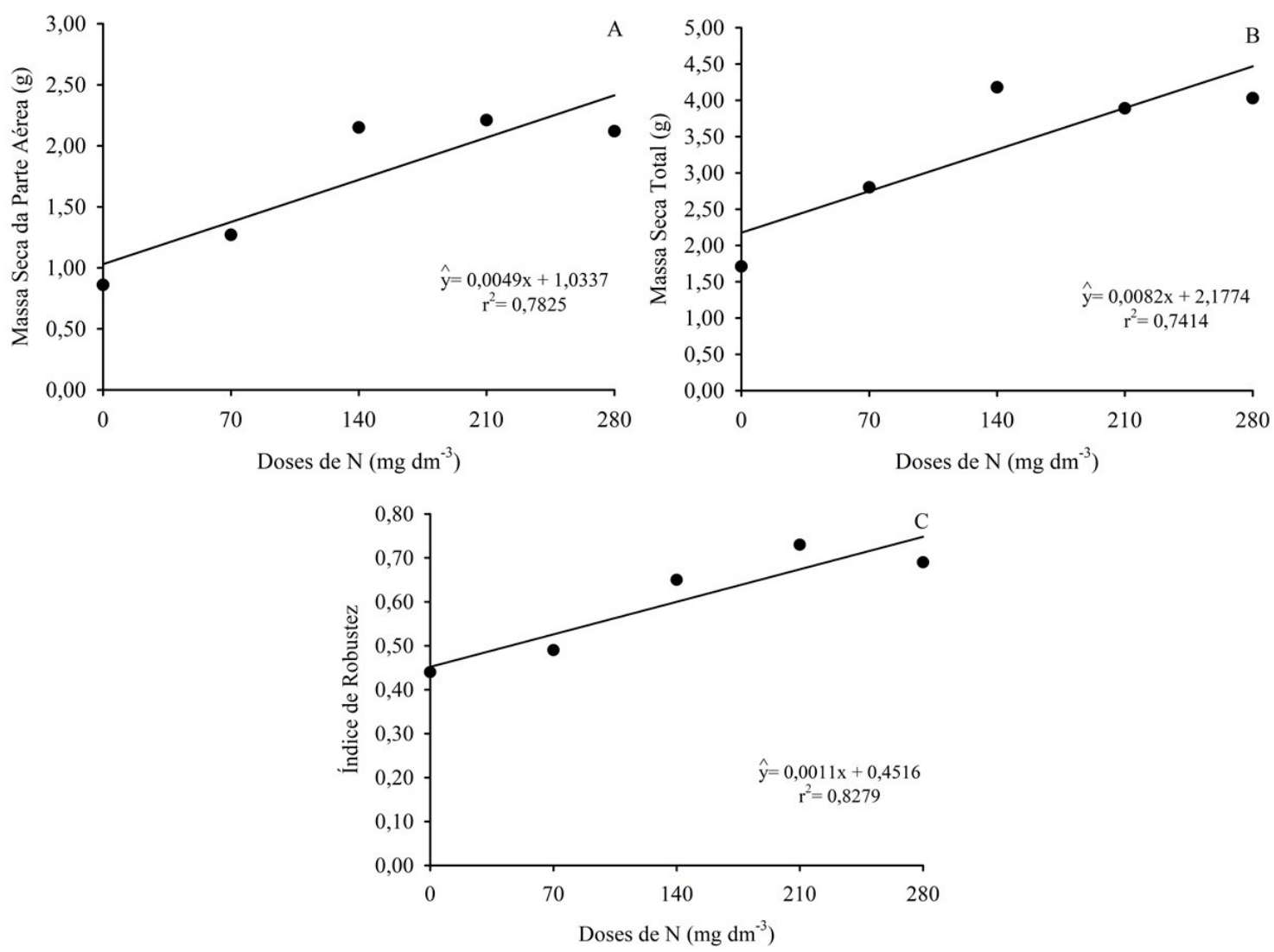

Quanto à MSF de M. tenuiflora, verificou-se resposta significativa à aplicação das doses de $\mathrm{N}$, apresentando resposta linear $(\mathrm{p}<0,05)$. Mudas de Samanea inopinata também responderam positivamente à aplicação de nitrogênio ao substrato, propiciando consideráveis aumentos na produção de matéria seca das folhas (Cruz et al. 2006). Já em mudas de Apuleia leiocarpa não foi verificada resposta significativa à aplicação de N (Nicoloso et al. 2001). O efeito significativo na MSF pode ser resultado do maior crescimento vegetativo das plantas, o que também teria colaborado para a maior MSPA. A aplicação de doses de $\mathrm{N}$ mostra-se interessante, pois afeta diretamente a capacidade fotossintética das plantas, estando também relacionado aos outros incrementos em dados biométricos (Belapart et al. 2013).

A análise de regressão indicou resposta significativa das mudas de $M$. tenuiflora para as doses de nitrogênio em relação à MSPA, apresentando modelo linear, e respondendo positivamente a adubação nitrogenada com o aumento das doses. Este aumento no substrato proporciona incremento na massa seca da parte aérea, principalmente quando existe deficiência deste nutriente (Freiberger et al. 2013), explicando o fato do maior valor de MSPA ter sido obtido justamente nas mudas adubadas com a maior dose de N (Benedetti et al. 2009), sendo a $M$. tenuiflora considerada exigente para este nutriente, uma vez que a sua ausência afeta a produção de MSPA. Mudas de Dalbergia nigra apresentaram resultado diferente, sendo verificado efeito quadrático com uma variação de MSPA de 0,42 a 3,72 g, quando a dose aplicada foi de zero (controle) a $200 \mathrm{mg} \mathrm{dm}^{-3} \mathrm{de} \mathrm{N}$ (Marques et al. 2006). Estimando a dose de $200 \mathrm{mg} \mathrm{dm}^{-3} \mathrm{de} \mathrm{N}$ para M. tenuiflora a MSPA chegaria a $2,01 \mathrm{~g}$. 
Para a MST, verificou-se efeito significativo para a aplicação das doses de $\mathrm{N}$ em mudas de $M$. tenuiflora, apresentando resposta linear com o acréscimo das doses $(\mathrm{p}<0,05)$. Doses de $\mathrm{N}$ nas mudas de $M$. caesalpiniifolia cultivadas em dois substratos diferentes (Cambissolo e Latossolo vermelho-amarelo) também apresentaram ajuste ao modelo linear de regressão, no peso seco total, conforme o acréscimo das doses de N (Marques et al. 2006). Isso foi verificado em mudas de Dalbergia nigra, onde houve produção crescente conforme o acréscimo das doses (Marques et al. 2006). No entanto, Nicoloso et al. (2005), quando estudaram a nutrição de mudas de Apuleia leiocarpa, verificaram redução na MST da planta. Ainda, segundo estes mesmos autores, a nutrição com sulfato de amônio tende a acidificar o citosol das células radiculares e na rizosfera. Entretanto isso não foi constatado no presente trabalho.

A análise de regressão apresentou resposta linear à aplicação das doses de $\mathrm{N}$, comprovando a influência da adubação nitrogenada para o IR. Valores ideais para essa relação devem situar entre 5,4 e 8,1, indicando o equilíbrio de crescimento das mudas (Carneiro 1995). Com o aumento das doses, verificou-se efeito significativo, ocorrendo um acréscimo nos valores desta relação, apresentando uma variação entre as médias de 4,87 a 7,32. Assim, os valores encontrados neste trabalho, para esse parâmetro, são considerados dentro do limite ideal para a qualidade de mudas.

Resultado semelhante foi encontrado por Dutra et al. (2015) quando trabalharam com mudas de Dalbergia miscolobium, aplicando doses de $\mathrm{N}$ as mudas, também verificaram valores dentro do limite ideal, o que garante menor probabilidade de tombamento, e melhor estabelecimento em campo. A dose de $300 \mathrm{mg} \mathrm{dm}^{-3}$, utilizada para a D. miscolobium, situou-se entre 5 e 6 estando, portanto, dentro da faixa que comprova a qualidade das mudas.

O desenvolvimento de mudas de $M$. tenuiflora é eficiente com a inoculação do rizóbio específico (M. tenuiflora). Portanto, a adição de nitrogênio sintético é recomendada apenas como alternativa secundária, sendo a dose de $210 \mathrm{mg} \mathrm{dm}^{-3}$ a mais indicada, por proporcionar melhor desenvolvimento associado a redução nos dispêndios na produção de mudas de $M$. tenniflora.

\section{ConClusões}

O inóculo de $M$. tenuiflora (rizóbio específico) se mostrou eficiente na produção de mudas de $M$. tenuiflora, diferente dos demais inóculos, que não apresentaram efeito positivo no desenvolvimento das mudas em nenhum dos parâmetros estudados.

As mudas responderam a adubação nitrogenada proveniente do sulfato de amônio, sendo a dose $210 \mathrm{mg}$ $\mathrm{dm}^{-3}$ a que proporcionou maiores valores de crescimento e, portanto, sendo a mais indicada para a produção de mudas de M. tenuiflora.

\section{Agradecimentos}

Gerência de Meio ambiente do Centro de Pesquisa e Desenvolvimento Leopoldo Américo Miguez de Melo (CENPES) da Petrobras.

\section{REFERÊNCIAS}

Almeida GS, Nascimento LO, Almeida AS, Cardoso JF, Leal FA. 2013. Capacidade de nodulação em ingá sp. de ocorrência na amazônia ocidental. Enciclopédia Biosfera, 9(17):491. 
Alves JJA, Araújo MA, Nascimento SS. 2009. Degradação da Caatinga: Uma investigação ecogeográfica. Revista Caatinga, 22(3):126-135.

Antunes JEL, Gomes RLF, Lopes ACA, Araújo ASF, Lyra MCCP, Figueiredo MVB. 2011. Eficiência simbiótica de isolados de rizóbio noduladores de feijão-fava (Phaseolus lunatus L.). Revista Brasileira de Ciência do Solo, 35(3):751-757. doi. org/10.1590/S0100-06832011000300011

Araъjo ASF, Carneiro RFV, Bezerra AAC, Аraъjo FF. 2010. Coinoculaзго rizybio $\boldsymbol{e}$ Bacillus subtilis $\boldsymbol{e}$ m feijão-caupi e leucena: efeito sobre a nodulaзго, а ғіхазго de $\mathrm{N}_{2}$ e o crescimento das plantas. Ciência Rural, 40(1):182-185. doi: 10.1590/S0103-84782009005000249

Belapart D, Leite SMM, Girotto MD, Pedrone LP. 2013. Efeito de diferentes doses de nitrogênio e cálcio no desenvolvimento inicial do guanandi. Unimar Ciências, 22(1/2):71-77.

Benedetti EL, Santin CWD, Sereda F, Roveda LF, Serrat BM. 2009. Crescimento e sintomas em mudas de espinheira-santa com omissão de nitrogênio, fósforo e potássio. Floresta, 39(2):335-343. doi.org/10.5380/rf.v30i2.14560

Benedito CP, Ribeiro MCC, Torres SB, Guimarães IP, Oliveira KJB. 2017. Dormancy overcoming, temperatures and substrates on germination of Mimosa tenuiflora Willd seeds. Semina: Ciências Agrárias, 38(1):125-134. doi:10.5433/16790359.2017v38n1p125

Bezerra DAC, Rodrigues FFG, Costa JGM, Pereira AV, Sousa EO, Rodrigues OG. 2011. Abordagem fitoquímica, composição bromatológica e atividade antibacteriana de Mimosa tenuiflora (Wild) Poiret e Piptadenia stipulacea (Benth) Ducke. Acta Scientiarum. Biological Sciences, 33(1):99-106. doi:10.4025/actascibiolsci.v33i1.5366

Cadorin DA, Malavasi UC, Coutinho PWR, Dranski JAL, Malavasi MM. 2015. Metil Jasmonato e flexões caulinares na rustificação e crescimento inicial de mudas de Cordia trichotoma. Cerne, 21(4): 657-664. doi.org/10.1590/010477602015210 42029.

Cameron KC, Di HJ, Moir JL. 2013. Nitrogen losses from the soil/plant system: A review. Annals of Applied Biology, 162(2): 145-173.

Carneiro JGA. 1995. Produção e controle de qualidade de mudas florestais. UFPR/FUPEF, 451 p.

Carvalho FG, Selbach PA, Silva AJN. 2008. ESPECIFICIDADE HOSPEDEIRA DE VARIANTES Bradyrbizobium SPP EM SOJA (CVS PEKING E CLARK), CAUPI E GUANDU. Revista Brasileira de Ciência do Solo, 32(n. especial):2701-2708. doi.org/10.1590/S0100-06832008000700013.

Chaves LLB, Carneiro JGA, Barroso DG, Leles PSS. 2003. EFEITOS DA INOCULAÇÃO COM RIZÓBIO E DA ADUBAÇÃO NITROGENADA NA PRODUÇÃO DE MUDAS DE SESBÂNIA EM SUBSTRATO CONSTITUÍDO DE RESÍDUOS AGROINDUSTRIAIS. Revista Árvore, 27(4):443-449. doi.org/10.1590/S010067622003000400004

Chaves LLB, Carneiro JGA, Barroso DG. 2006. Crescimento de mudas de Anadenanthera macrocarpa (Benth) Brenan (angico-vermelho) em substrato fertilizado e inoculado com rizóbio. Revista Árvore, 30(6):911-919. doi:10.1590/S010067622006000600006 .

Chaves LLB, Carneiro JGA, Barroso DG. 2006. Crescimento de mudas de angico vermelho produzidas em substrato fertilizado, constituído de resíduos agro-industriais. Scientia Forestalis, (72):49-56. 
Ciriello V, Guerrini IA, Backes C. 2014. Doses de nitrogênio no crescimento inicial e nutrição de plantas de guanandi. Cerne, 20(4):653-660. doi: 10.1590/01047760201420041445

Cruz CAF, Paiva HN, Guerrero CRA. 2006. Efeito da adubação nitrogenada na produção de mudas de sete-cascas (Samanea inopinata (Harms) Ducke). Revista Árvore, 30(4):537-546. doi.org/10.1590/S0100-67622006000400006

Delarmelina WM, Caldeira MVW, Faria JCT, Lacerda LC. 2015. Uso de resíduo orgânico em substrato para produção de Chamaecrista desvauxii (Collad.) Killip var. latistipula (Benth.). Cerne, 21(3):429-437. doi:10.1590/01047760201521031439

Dias PC, Pereira MSF, Kasuya MCM, Paiva HN, Oliveira LS, Xavier A. 2012. MICORRIZA ARBUSCULAR E RIZÓBIOS NO ENRAIZAMENTO E NUTRIÇÃO DE MUDAS DE ANGICO-VERMELHO. Revista Árvore, 36(6): 1027-1037. doi:10.1590/S0100-67622012000600004

Dutra TR, Massad MD, Matos OS, Sarmento MFQ, Oliveira JC. 2015. Crescimento inicial e qualidade de mudas de caviúna-do-cerrado e caroba-do campo em resposta à adubação nitrogenada. Agropecuária Científica no Semiárido, 11(3):52-61.

EMBRAPA AGROBIOLOGIA. Inoculantes bacterianos. Disponível em: https://www.embrapa.br/busca-de-solucoestecnologicas/-/produto-servico/3726/inoculantes-bacterianos. Acesso em: 12 Abril 2019.

Fernandes MRM, Nóbrega RSA, Fernandes MM, Sousa WC, José Filho FL. 2017. Substratos e inoculação com Bradyrbiz̧obium no crescimento de tamboril (Enterolobium contortisiliquum) em área degradada. Revista Agrarian, 10(35):52-60.

Ferreira LVM, Nóbrega RSA, Silva GC, Costa EM, Nóbrega JCA, Moreira FMS. 2015. Crescimento e nodulação de Sesbania virgata com estirpes nativas e introduzidas. Revista de Ciências Agrárias, 58(4):327-334. doi.org/10.4322/rca.1881

Ferreira PAA, Bomfeti CA, Silva Júnior R, Soares BL, Soares CRFS, Moreira FMS. 2012. Eficiência simbiótica de estirpes de Cupriavidus necator tolerantes a zinco, cádmio, cobre e chumbo. Pesquisa Agropecuária Brasileira, 47(1):85-95. doi. org/10.1590/S0100-204X2012000100012

Franco AA, Faria SM. 1997. The contribution of N2-fixing tree legumes to land reclamation and sustainability in the tropics. Soil Biology and Biochemistry, 29(5/6):897-903. doi.org/10.1016/S0038-0717(96)00229-5

Freiberger MB, Guerrini IA, Galetti G, Fernandes DM, Corrêa JC. 2013. Crescimento inicial e nutrição de cedro (Cedrela fissilis Vell.) em função de doses de nitrogênio. Revista Árvore, 37(3):385-392.

Góes GS, Gross E, Rocha EB, Mielke MS. 2015. Efeitos da inoculação com bactérias diazotróficas e da adubação nitrogenada no crescimento e na qualidade de mudas de Inga laurina (SW.) Willd. (Fabaceae). Revista Árvore, 39(6):1031-1038. doi. org/10.1590/0100-67622015000600005

Hoagland DR, ARNON DI. 1950. The Water Culture Method for Growing Plants sithout Soil. California Agricultural Experiment Station, 347(2):32.

Jayakumar P, Tan TK. 2006. Variations in the responses of Acacia mangium to inoculation with different strains of Bradyrhizobium sp. under nursery conditions. Symbiosis, 41(1):31-37.

Lima KDR, Chaer GM, Rows JRC, Mendonça V, Resende AS. 2015. Seleção de espécies arbóreas para revegetação de áreas degradadas por mineração de piçarra na Caatinga. Revista Caatinga, 28(1):203-213. 
Lucangeli C, Bottini R. 1997. Effects of Azospirillum spp. on endogenous gibberellin content and growth of maize (Zea mays L.) treated with uniconazole. Symbiosis, 23(1):63-72.

Machado AT, Sodek L, Dobereiner J, Reis VM. 1998. EFEITO DA ADUBAÇÃO NITROGENADA E DA INOCULAÇÃO COM BACTÉRIAS DIAZOTRÓFICAS NO COMPORTAMENTO BIOQUÍMICO DA CULTIVAR DE MILHO NITROFLINT. Pesquisa Agropecuária Brasileira, 33(6):961-970.

Maia GN. 2004. Caatinga: árvores e arbustos e suas utilidades, D\&Z Computação, São Paulo: 413 p.

Maia J, Scotti MR. 2010. Growth of Inga vera Willd. subsp. affinis under rizobia inoculation. Revista de la Ciência del Suelo y Nutrición Vegetal, 10(2):139-149. doi.org/10.4067/S0718-27912010000200005

Mañas PP, Castro E, Hera JL. 2009. Quality of maritime pine (Pinus pinaster Ait.) seedlings using waste materials as nursery growing media. New Forests, 37(3):295-311. doi:10.1007/s11056-008-9125-4

Marques VB, Paiva HN, Gomes JM, Neves JCL. 2006. Efeitos de fontes e doses de nitrogênio no crescimento de mudas de sabiá (Mimosa caesalpiniaefolia Benth.). Scientia Forestalis, (71):77-85.

Martins LMV, Xavier GR, Neves MCP, Rumjanek NG. 1997. CARACTERÍSTICAS RELATIVAS AO CRESCIMENTO EM MEIO DE CULTURA E A MORFOLOGIA DE COLÔNIAS DE “RIZÓBIO”. Seropédica, RJ: Empresa Brasileira de Pesquisa Agropecuária, (Embrapa-CNPAB. Comunicado Técnico, 19), p. 14

Mendes MMC, Chaves LFC, Tarcísio Neto PP, Silva JAA, Figueiredo MVB. 2013. Crescimento e sobrevivência de mudas de sabiá (Mimosa caesalpiniaefolia Benth.) inoculadas com micro-organismos simbiontes em condições de campo. Ciência Florestal, 23(2):309-320. doi.org/10.5902/198050989277

Nicoloso FT, Fogaça MAF, Zanchetti F, Missio E. 2001. NUTRIÇÃO MINERAL DE MUDAS DE GRÁPIA (Apuleia leiocarpa) EM ARGISSOLO VERMELHO DISTRÓFICO ARÊNICO: (1) Efeito da dubaçio NPK no crescimento. Ciência Rural, 31(6):1-8.

Nicoloso FT, Sartori L, Jucoski LSA, Cervi FG. 2005. FONTES DE NITROGÊNIO MINERAL (N-NO3 - e N-NH4 + ) NO CRESCIMENTO DE MUDAS DE GRÁPIA (Apuleia leiocarpa (Vog.) Macbride). Ciência Florestal, 15(3):221-231. doi. org/10.5902/198050981839

Nobre AP. 2008. Respostas de mudas de Gliricidia sepium à aplicação de nitrogênio e fósforo. Dissertação (Mestrado) - Universidade Federal de Campina Grande, Patos 56 p.

Oliveira E, Vital BR, Pimenta AS, Della RML, Ladeira AMM, Carneiro ACO. 2006. Estrutura anatômica da madeira e qualidade do carvão de Mimosa tenuiflora (Willd.) Poir. Revista Árvore, 30(2):311-318.

Saikia SP, Dutta SP, Goswami A, Bhau BS, Kanjilal PB. 2010. Role of Azospirillum in the Improvement of Legumes. In: Khan MS, Zaidi A, Musarrat J. Microbes for Legume Improvement. Springer-Verlag, 389-408.

Silva VN, Silva LESF, Figueiredo MVB. 2006. Atuação de rizóbios com rizobactéria promotora de crescimento em plantas na cultura do caupi (Vigna unguiculata [L.] Walp.). Acta Scientiarum. Agronomy, 28(3):407-412.

Smarsi RC, Oliveira GF, Reis LL, Chagas EA, Pio R, Mendonça V, Chagas PC, Curi PN. 2011. Efeito da adubação nitrogenada na produção de mudas de lichieira. Revista Ceres, 58(1):129-131. 
Tavares SRL, Franco AA, Silva EMR. 2016. Resposta de sabiá Mimosa caesalpiniaefolia benth. a inoculações com rizóbio e micorriza em diferentes níveis de fósforo em solo de restinga degradado. HOLOS, 4:36-55.

Vieira EP, Souza LAG. 2011. Inoculação com rizóbios em mudas de acapu do igapó e saboarana. Revista de Ciências Agrárias, 54(1):52-60. doi:10.4322/rca.2011.038 